\title{
Clinicopathological Features of Extranodal Lymphomas: Kuwait Experience
}

\author{
L. Temmim ${ }^{a}$ H. Baker ${ }^{a, b} \quad$ H. Amanguno ${ }^{a} \quad$ J.P. Madda ${ }^{c}$ F. Sinowatz ${ }^{d}$ \\ ${ }^{a}$ Hussain Makki Al Jummaa Cancer Center, Safat, Kuwait; ${ }^{b}$ King Faisal Specialist Hospital and Research Center, \\ Riyadh, Saudi Arabia; ${ }^{\mathrm{c}} \mathrm{Al}$-Amiri Hospital, Safat, Kuwait; ${ }^{\mathrm{d}}$ Department of Histology and Embryology, University \\ of Munich, Munich, Germany
}

\section{Key Words}

Extranodal lymphomas · Clinico-pathological

features $\cdot$ Kuwait

\begin{abstract}
A total of 935 patients with extranodal non-Hodgkin lymphoma (NHL) diagnosed in the period between January 1985 and December 2000 in Kuwait Cancer Center, serving the whole population of Kuwait, were used to describe the clinicopathological and epidemiological features of extranodal lymphomas in Kuwait. Extranodal lymphomas accounted for $45 \%$ of all NHL observed during this time. All NHL cases from Kuwait Cancer registry were analyzed and pathologically reclassified using the latest WHO (2000) classification. The most common lymphoma observed was diffuse large B-cell lymphoma $(58.60 \%)$ followed by Burkitt's lymphoma (BL) $(3.80 \%)$. In the pediatric group, $\mathrm{BL}$ comprises more than two thirds of all patients $(77.20 \%)$. The most common extranodal sites were stomach $(19.70 \%)$ and skin $(17.80 \%)$ in the adult group, large intestine $(29.80 \%)$ and small intestine $(19.30 \%)$ in the pediatric age group. The majority $(73.40 \%)$ of adult extranodal lymphomas was in stage IE-IIE and had a very good prognosis. On the contrary, the majority of pediatric extranodal lymphomas were found to be in stage III and IV. Variations in treatment
\end{abstract}

policies (single agent or combined chemotherapy, radiotherapy, combined modality treatment) adopted and changed during the time period of 16 years of this retrospective study were documented.

Copyright (C) 2004 S. Karger AG, Basel

\section{Introduction}

The incidence of non-Hodgkin lymphoma (NHL), especially at certain extranodal sites continues to rise [1] and the number of deaths attributable to these malignancies rank in the top five causes of cancer-related deaths in the United States [2]. Their increasing incidence is related to the environmental factors including occupational exposures and HIV infection [3]. NHL arises either in lymph nodes or in other lymphatic tissues, such as spleen and mediastinum ('nodal lymphomas'), or in lymphatic cells in other organs, such as tonsils and thymus ('extranodal lymphomas') [4].

The Age Standardized Incidence Rate (ASIR) of NHL as reported by the Kuwait Cancer Registry (2002) is $5.8 / 100,000$ in Kuwaiti males and 8.5/100,000 in Kuwaiti females. ASIR among non-Kuwaiti males is 4.6/100,000 and 3.5/100,000 among non-Kuwaiti females. NHL ranks as the third most common cancer in both Kuwaiti males (after leukemia and lung cancer) and

\section{KARGER \\ Fax +4161306 1234 E-Mailkarger@karger.ch} www.karger.com
(C) 2004 S. Karger AG, Basel 0030-2414/04/0676-0382\$21.00/0

Accessible online at:

www.karger.com/ocl
Dr. Labiba Temmim

Hussain Makki Al Jummaa Cancer Center Kuwait

P.O. Box 21074, 13071 Safat (Kuwait)

Tel. +965 67870 00, +965 24558 01, ext. 219, Fax +965 2427617

E-Mail labibakccc@hotmail.com or cfg@habchal.com.kw 
Kuwaiti and non-Kuwaiti females (after breast and thyroid cancer). NHL ranks two in male non-Kuwaiti patients after lung cancer.

The incidence of NHL arising from an extranodal tissue has been reported to be increasing in several countries $[1,5]$ and yet the epidemiology of this heterogeneous disease has been poorly described. Over the past three decades, immunology, cytomorphological and genetic diagnostic techniques have continuously refined our current understanding of neoplasia of the immune system [6]. Differences in presentation, behavior and survival between NHL of nodal and extranodal sites have led several authors to suggest that nodal and extranodal diseases should be considered as distinct entities with differing etiologies [7-9]. Although 25-45\% of patients of NHL present with a primary extranodal lymphoma [4, 7-10], and numerous papers dealing with extranodal NHL originating in almost every organ in the body have been published, the literature on primary extranodal lymphomas as a group is limited [10]. In Kuwait, the incidence of extranodal lymphomas is $45 \%$ of all lymphomas registered during the last 16 years. In this retrospective study, the comprehensive data collected at the Hussain Makki Al Jummaa Cancer Center, the only institution serving the whole population of Kuwait, and the registries of all main general hospitals of Kuwait were evaluated to describe the epidemiology and pathoclinical features of extranodal lymphomas in Kuwait in the period from 1985 to 2000.

\section{Material and Methods}

Clinicopathological data and site-specific information on NHL were obtained from registries of the Hussain Makki Al Jummaa Cancer Center in Kuwait, general hospitals in Kuwait and from patients outside of Kuwait referred to Kuwait Cancer Control Center (KCCC) for the treatment of their disease. A total of 935 patients with extranodal NHL diagnosed in the period between January 1985 and December 2000 in KCCC were studied. The information included age of the patients, sex, ethnic origin, date and site of the diagnostic biopsies, primary extranodal site of involvement, including lymphatic sites when positive, performance status, diameter of the largest tumor mass and Ann Arbor stage.

Laboratory data recorded included: serum lactate dehydrogenase level, absolute lymphocyte count, presence of circulating lymphoma cells, history of immunodeficiency (HTLV-1), human immunodeficiency virus status, hepatitis screening, bone marrow aspiration and biopsy.

Radiological investigations comprised of CT scan for chest, pelvis and abdomen. The neck was included when indicated. In selected cases additional studies were performed: gallium scan, ST scan or MRI of brain, upper and lower GIT endoscopies, in cases with symptoms of GIT lymphomas or when tonsils of Waldeyer's ring were involved. For special indications diagnostic lumbar punctures (CSF examination, cytology and chemistry) were performed.

\section{Staging}

The clinical stage at the time of initial diagnosis of the lymphomas was defined according to the Ann Arbor classification. Involvement of lymph nodes and mediastinum were defined as nodal localizations, and the involvement of other organs was defined as extranodal. Patient's were considered to be completely staged when adequate information was available on history, status of peripheral lymph nodes (physical examination), Waldeyer's ring examination, mediastinal lymph nodes (chest X-ray), abdominal lymph nodes, liver and spleen (abdominal CT scan) as well as on peripheral blood and bone marrow (cytology and histology).

\section{Histopathological Evaluation}

Routine hematoxylin-eosin stained sections were evaluated in all cases to assess general pathomorphological features. In addition to hematoxylin-eosin staining, immunophenotyping of all lymphomas was routinely done in our laboratory. Immunohistochemical studies were performed on paraffin-embedded tissue (extranodal sites and/or involved lymph nodes) from all patients using a threestage immuno-peroxidase technique after antigen retrieval by microwaving the slides in citrate buffer for $35 \mathrm{~min}$. Primary antibodies (obtained from Zymed Laboratories, San Francisco, Calif., USA) were used in this study:

The basic NHL screen panel to determine B- or T-cell phenotype in our practice included CD20 and CD3; A more accurate classification of NHL was achieved by using other different markers:

In cases of small cell NHL, the panel included CD5, CD21, CD23 bcl-2, PRAD1, and $\kappa$ and $\lambda$ light chains.

Antibodies to CD15, CD30, CD45, EMA, and anaplastic lymphoma kinase were used to differentiate between peripheral T-cell lymphoma, anaplastic lymphoma and Hodgkin's lymphoma.

In case of NHL with plasmocytic or plasmocytoid differentiation, antibodies to $\kappa$ and $\lambda$ light chains were used to confirm the diagnosis of these subtypes.

tDt, CD5, CD43, PRAD1, peroxidase or lysozyme were used to differentiate between lymphoblastic lymphoma, mantle cell lymphoma, and granulocytic sarcoma.

Additional immunostaining that was helpful for differential diagnosis included cytokeratin, LCA (CD45), Ki-67 (M1B1), bcl-2, CD34, c-myc, CD10 and bcl-6.

Positive controls were prepared using paraffin-embedded tissue sections with proven good reactivity. Negative controls were performed by substituting the respective primary antibody by nonimmune serum. All cases were classified or reclassified according to the 2001 WHO Classification.

\section{Therapy}

The initial therapy and therapeutic response [complete response (CR), partial response (PR), progressive disease (PD), no response or relapse, subsequent therapies and follow-up] were accurately documented for each case. A CR to treatment was defined by the disappearance of all clinical evidence of disease and normalization of all laboratory values and radiographical results that had been abnormal before treatment. Treatment outcome was measured using overall survival. It was measured as the interval 
between the beginning of treatment and death or the date of the last follow-up evaluation. Patients were usually seen every 2 months in the first year, every 3 or 4 months in the second and following years.

\section{Results}

From a total of 935 patients with extranodal lymphomas $821(87.8 \%)$ were in the adult age group, $114(12.2 \%)$ in the pediatric group (table 1). Fifty-nine percent of the pediatric extranodal lymphomas were diagnosed in patients between 6 months and 6 years. The majority (58.8\%) were 3-6 years old. The male to female ratio in the adult age group (2.1: 1) and in the pediatric group (2.0: 1) were similar. Kuwaiti patients accounted for $324(39.5 \%)$ of the adult age group and 47 (41.2\%) of the pediatric age group. The number of non-Kuwaiti patients included in our study was 504. Four hundred and twenty-eight were of Arabic origin ( 368 adults and 60 children), the 136 remaining patients (129 adults and 7 children) originated from non-Arab origin (different Asian countries). Median follow-up time was 47.0 months, with a range of $1-170$ months.

Patients who presented with extranodal NHL had localizations in a wide variety of organs (table 2). The digestive tract (stomach 19.8\%; small intestine 9.8\% and colon/rectum 5.8\%) and the skin (17.8\%) were the sites most frequently involved. In children, 57 cases $(50 \%)$ of primary bowel lymphoma were observed (table 3 ). The majority affected the large intestine (30.7\%), mainly at the ileocecal junction. $17.8 \%$ involved the small intestine, mainly the ileum. Bulky disease was found in $47.5 \%$ of the adult age group. In 129 cases (15.7\%), the tumor mass was equal or larger than $10 \mathrm{~cm}$ in diameter. A much higher percentage of bulky disease was found in children. $61.4 \%$ of the patients in the pediatric group displayed bulky disease, 22 of them (19.3\%) had tumors equal or larger than $10 \mathrm{~cm}$ in diameter. The majority of NHL in adults (table 4) was DLBCL (58.6\%), followed by MF $(14.4 \%)$. In the pediatric group more than two thirds (77.2\%) were Burkitt's lymphoma (BL). DLBCL was also important with a percentage of $14.0 \%$.

Most of the patients ( $73.6 \%$ of the adults and $88.6 \%$ of the children) received chemotherapy treatment (table 5). Radiotherapy was used in adults in $7.3 \%$ of cases. A combination of chemotherapy and radiotherapy was performed in $22.8 \%$ of the adults and $10.5 \%$ of the children. Many patients responded favorably to the therapy: $71.4 \%$ of the adults and $63.2 \%$ of the children showed a CR, and
Table 1. Clinical and pathological features of extranodal lymphomas

\begin{tabular}{|c|c|c|}
\hline Clinical presentation & Adults & Pediatric $(0-15)$ \\
\hline Number & $821(87.8 \%)$ & $114(12.2)$ \\
\hline \multicolumn{3}{|l|}{ Sex } \\
\hline Male & $559(68.1 \%)$ & $76(66.7 \%)$ \\
\hline Female & $262(31.9 \%)$ & $38(33, .3 \%)$ \\
\hline \multicolumn{3}{|l|}{ Age groups (years) } \\
\hline $0-5$ & & $43(37.7)$ \\
\hline $5-9$ & & $37(32.5)$ \\
\hline $10-19$ & $39(4.8)$ & $34(29.8)$ \\
\hline $20-29$ & $127(15.5)$ & \\
\hline $30-39$ & $178(21.7)$ & \\
\hline $40-49$ & $167(20.3)$ & \\
\hline $50-59$ & $134(17.4)$ & \\
\hline $60+$ & $167(20.3)$ & \\
\hline \multirow[t]{3}{*}{ Extranodal sites } & Stomach: $19.7 \%$ & Bowel: $50.0 \%$ \\
\hline & Skin: $17.8 \%$ & Pharynx: $12.3 \%$ \\
\hline & $\begin{array}{l}\text { Small intestine: } \\
9.8 \%\end{array}$ & Ovary: $9.6 \%$ \\
\hline Nodal involvement & $493(60 \%)$ & $101(57.9)$ \\
\hline \multicolumn{3}{|l|}{$\mathrm{LDH}$} \\
\hline High & $330(40.2 \%)$ & $66(57.9 \%)$ \\
\hline Normal & $491(59.8 \%)$ & $48(42.1 \%)$ \\
\hline Performance status & $772(94.0 \%)$ & $106(93.0 \%)$ \\
\hline Systemic status & $321(39.1 \%)$ & $71(62.3 \%)$ \\
\hline Fever & $246(30.0 \%)$ & $63(55.3 \%)$ \\
\hline Weight loss & $223(27.2 \%)$ & $53(46.5 \%)$ \\
\hline \multirow[t]{2}{*}{ Stage } & IE $33.1 \%$ & III $37.6 \%$ \\
\hline & IIE $40.3 \%$ & IV $27.7 \%$ \\
\hline Bulky disease & $392(47.8 \%)$ & $72(63.2 \%)$ \\
\hline$>10 \mathrm{~cm}$ & $132(33.7 \%)$ & $23(32.0 \%)$ \\
\hline
\end{tabular}

$12.8 \%$ of adults and $14.1 \%$ in the pediatric group showed at least a partial response. No response was seen in $21.9 \%$ of the children and $13.6 \%$ of the adults. $27.5 \%$ of the patients in the adult group during the observed period, and a considerably higher percentage of the children (39.5\%) did not survive.

A positive family history was found in 8 cases of adult patients (table 5). Four were males and four were females. Median age was 48 years, ranging from 15 to 65 years. Stomach lymphoma represents $37.5 \%$ followed by thymus $25.0 \%$, one case of heart, tonsil and skin MF. Most of the cases were Kuwaitis. They represented $75 \%$, and the remaining $25 \%$ were Jordanians. $75 \%$ of the family 
Table 2. Localization, frequency and percentage of site (organ) involvement of primary extranodal lymphomas in adults
Table 3. Localization, frequency and percentage of site (organs) of primary extranodal lymphoma in pediatric age group

\begin{tabular}{|c|c|c|c|c|c|c|c|c|}
\hline \multirow[t]{2}{*}{ Site } & \multicolumn{2}{|c|}{ Kuwaiti } & \multicolumn{2}{|c|}{ Arab } & \multicolumn{2}{|c|}{ Non--Arab } & \multicolumn{2}{|c|}{ Total } \\
\hline & $\mathrm{n}$ & $\%$ & $\mathrm{n}$ & $\%$ & $\mathrm{n}$ & $\%$ & $\mathrm{n}$ & $\%$ \\
\hline Stomach & 68 & 21.0 & 79 & 21.2 & 16 & 12.8 & 163 & 19.8 \\
\hline Skin & 72 & 22.2 & 56 & 15.1 & 18 & 14.4 & 146 & 17.8 \\
\hline Small intestine & 20 & 6.2 & 35 & 9.4 & 25 & 20.0 & 80 & 9.8 \\
\hline Waldeyer's ring & 20 & 3.1 & 38 & 7.8 & 14 & 9.6 & 72 & 8.8 \\
\hline Bone/Soft tissue & 24 & 7.4 & 24 & 6.5 & 13 & 10.4 & 61 & 7.4 \\
\hline Colon/Rectum & 15 & 4.7 & 22 & 5.9 & 10 & 8.0 & 47 & 5.8 \\
\hline Brain/CNS & 7 & 2.2 & 19 & 5.1 & 5 & 4.0 & 31 & 3.8 \\
\hline Salivary/Lacrimal gland & 17 & 5.2 & 11 & 3.0 & 2 & 1.6 & 30 & 3.7 \\
\hline Thyroid & 13 & 4.0 & 11 & 3.0 & 1 & 0.8 & 25 & 3.0 \\
\hline Thymus & 7 & 2.2 & 8 & 2.2 & 7 & 5.6 & 22 & 2.7 \\
\hline Spleen & 8 & 2.5 & 12 & 3.2 & 1 & 0.8 & 21 & 2.6 \\
\hline Oral Cavity & 7 & 2.2 & 7 & 1.9 & 3 & 2.4 & 17 & 2.0 \\
\hline Liver & 5 & 1.5 & 10 & 2.7 & 1 & 0.8 & 16 & 1.9 \\
\hline Kidney & 6 & 1.9 & 9 & 2.4 & 0 & 0.0 & 15 & 1.8 \\
\hline Testis & 8 & 2.5 & 6 & 1.6 & 0 & 0.0 & 14 & 1.7 \\
\hline Pancreas & 7 & 2.2 & 3 & 0.8 & 3 & 2.4 & 13 & 1.6 \\
\hline Lung/Pleura & 6 & 1.9 & 4 & 1.1 & 1 & 0.8 & 11 & 1.3 \\
\hline Cervix/Vagina & 4 & 1.2 & 4 & 1.1 & 2 & 1.6 & 10 & 1.2 \\
\hline Accessory inuses & 1 & 0.3 & 7 & 1.9 & 0 & 0.0 & 8 & 1.0 \\
\hline Ovary & 1 & 0.3 & 2 & 0.5 & 2 & 1.6 & 5 & 0.6 \\
\hline Heart & 3 & 0.9 & 1 & 0.3 & 0 & 0.0 & 4 & 0.5 \\
\hline Breast & 3 & 0.9 & 1 & 0.3 & 0 & 0.0 & 4 & 0.5 \\
\hline Urinary bladder & 2 & 0.6 & 0 & 0.0 & 0 & 0.0 & 2 & 0.2 \\
\hline Prostate & 0 & 0.0 & 1 & 0.3 & 0 & 0.0 & 1 & 0.1 \\
\hline Larynx & 0 & 0.0 & 1 & 0.3 & 0 & 0.0 & 1 & 0.1 \\
\hline Bone marrow & 0 & 0.0 & 1 & 0.3 & 0 & 0.0 & 1 & 0.1 \\
\hline
\end{tabular}

\begin{tabular}{|c|c|c|c|c|c|c|c|c|}
\hline \multirow[t]{2}{*}{ Site } & \multicolumn{2}{|c|}{ Kuwaiti } & \multicolumn{2}{|c|}{ Arab } & \multicolumn{2}{|c|}{ Non--Arab } & \multicolumn{2}{|c|}{ Total } \\
\hline & $\mathrm{n}$ & $\%$ & $\mathrm{n}$ & $\%$ & $\mathrm{n}$ & $\%$ & $\mathrm{n}$ & $\%$ \\
\hline Intestine & 21 & 44.7 & 30 & 50.0 & 6 & 85.7 & 57 & 50.0 \\
\hline Pharynx & 6 & 12.8 & 9 & & 0 & 0.0 & 15 & 12.3 \\
\hline Ovary & 5 & 10.6 & 6 & 10.0 & 0 & 0.0 & 11 & 9.6 \\
\hline Bone & 5 & 10.6 & 4 & 6.7 & 1 & 14.3 & 10 & 8.8 \\
\hline Thymus & 6 & 12.8 & 3 & 5.0 & 0 & 0.0 & 9 & 7.9 \\
\hline Testis & 1 & 2.1 & 7 & 11.7 & 0 & 0.0 & 8 & 7.0 \\
\hline Skin & 2 & 4.2 & 0 & 0.0 & 0 & 0.0 & 2 & 1.8 \\
\hline Kidney & 1 & 2.1 & 0 & 0.0 & 0 & 0.0 & 1 & 0.9 \\
\hline Parotid & 0 & 0.0 & 1 & 1.7 & 0 & 0.0 & 1 & 0.9 \\
\hline Accessory sinuses & 1 & 2.1 & 0 & 0.0 & 0 & 0.0 & 1 & 0.9 \\
\hline Total & 47 & & 60 & & 7 & & 114 & 100 \\
\hline
\end{tabular}

members affected were first degree relatives (mother, son, siblings) and the remaining 25\% were cousins. Lymphoma in the family members was mostly found in lymph nodes (75\%); the remaining $25 \%$ was in the stomach and spleen. Half of the lymphomas among family members were NHL, Hodgkin's lymphoma, respectively.
Eleven cases of extranodal lymphomas that evolved in patients who previously underwent organ transplantation could be documented. Eight cases (72.7\%) originated in males. Median age was 57 years, age range extended from 4 to 69 years. Regarding to the transplanted organ, most of the cases were kidney transplantations $(72.7 \%)$. Two 
Table 4. Histopathology of extranodal non-Hodgkin lymphomas

\begin{tabular}{|c|c|c|c|c|}
\hline \multirow{3}{*}{$\begin{array}{l}\text { Pathology } \\
\text { Diffuse large B-cell lymphoma } \\
\text { Mycosis fungoides }\end{array}$} & \multicolumn{2}{|c|}{ Adults } & \multicolumn{2}{|c|}{ Pediatrics } \\
\hline & 481 & $58.6 \%$ & 16 & $14.0 \%$ \\
\hline & 118 & $14.4 \%$ & 2 & $1.8 \%$ \\
\hline Marginal zone B Malt & 86 & $10.5 \%$ & & \\
\hline Marginal zone B Malt & 78 & $9.5 \%$ & & \\
\hline Composite marginal Zone/DLBC & 8 & $1.0 \%$ & & \\
\hline B follicular lymphoma & 38 & $4.6 \%$ & & \\
\hline $\mathrm{B}$ follicular lymphoma grade 1 & 13 & $1.6 \%$ & & \\
\hline B follicular lymphoma grade 2 & 3 & $0.4 \%$ & & \\
\hline B follicular lymphoma grade 3 & 10 & $1.2 \%$ & & \\
\hline Composite BFL3/DLBC & 12 & $1.5 \%$ & & \\
\hline Peripheral T-cell lymphoma & 31 & $3.8 \%$ & & \\
\hline Intestinal & 17 & $2.1 \%$ & & \\
\hline Peripheral T-cell lymphoma, unspecified & 12 & $1.5 \%$ & 1 & $0.9 \%$ \\
\hline Lymphoepithelial lymphoma & 2 & $0.2 \%$ & & \\
\hline Anaplastic large cell lymphoma & 16 & $3.5 \%$ & & \\
\hline T-anaplastic large cell & 13 & $1.6 \%$ & 1 & $0.9 \%$ \\
\hline B-anaplastic large cell & 3 & $0.4 \%$ & & \\
\hline Burkitt's lymphoma & 31 & $3.9 \%$ & 88 & $77.2 \%$ \\
\hline Small lymphocytic lymphoma & 9 & $1.1 \%$ & & \\
\hline Pre-T-lymphoblastic lymphoma & 3 & $0.4 \%$ & 2 & $1.8 \%$ \\
\hline Splenic marginal zone lymphoma & 3 & $0.4 \%$ & & \\
\hline Mantle cell lymphoma & 2 & $0.2 \%$ & & \\
\hline Intravascular lymphoma & 1 & $0.1 \%$ & & \\
\hline Pre-B-lymphoblastic lymphoma & 1 & $0.1 \%$ & & \\
\hline T-lymphoblastic lymphoma & 1 & $0.1 \%$ & 4 & $3.5 \%$ \\
\hline Total & 821 & $100 \%$ & 114 & $100 \%$ \\
\hline
\end{tabular}

of the other 3 remaining cases occurred after bone marrow transplantation and only one case was found after the transplantation of liver. $63.6 \%$ of the lymphomas seen after organ transplantation were DLBCL, 18.20\% were intestinal. Anaplastic large cell lymphoma and BL were represented by only one case each. Seven cases (63.60\%) of lymphomas post-transplantation were stage I-II, 4 cases $(36.40 \%)$ were stage III-IV. Median follow-up time for these patients was 5 months ranging from 1 to 60 months, with overall survival rate of $28.0 \pm 16.4$ after 12 months.

\section{Discussion}

NHL is one among the small number of malignant tumors with a markedly increasing incidence and mortality rates in the recent past. This trend is particularly obvious in industrialized countries [11], but is also seen in devel- oping countries. Iatrogenic immunosupression as well as numerous diseases associated with an impaired immune system, like acquired immunodeficiency syndrome, have been clearly recognized as etiological factors. Among the NHL, primary extranodal lymphomas are an important group of disease with diverse etiology, pathogenesis, pattern of presentation and outcome [12]. The gastrointestinal tract is the most common presenting site, but extranodal lymphomas have been virtually reported from every organ. Most are B-cell, DLCBL. Follicular histology is considerably less common.

In an extensive study, Newton et al. [4] described the epidemiology and geographical distribution of NHL in different countries. The authors used site-specific information of NHL from thirty-nine cancer centers in fourteen countries, including Kuwait. The incidence rate for all NHL combined varied from a low 2 per 100,000 per year in Thailand to about 10 per 100,000 in Caucasians in the USA. Across Europe, there was roughly a 2-fold 
Table 5. Therapies and course of extranodal lymphomas

\begin{tabular}{lcc}
\hline & Adults & Pediatric \\
\hline Number & $821(87.8 \%)$ & $114(12.2 \%)$ \\
\hline Initial therapy & & \\
CTH & $604(73.6 \%)$ & $101(88.6 \%)$ \\
RTH & $60(7.3 \%)$ & \\
Combination & $198(22.8 \%)$ & $12(10.5 \%)$ \\
Salvage & $187(22.8 \%)$ & $25(21.9 \%)$ \\
\hline Course & & \\
CR & $586(71.4 \%)$ & $72(63.2 \%)$ \\
PR & $105(12.8 \%)$ & $16(14.1 \%)$ \\
No response & $112(13.6 \%)$ & $25(21.9 \%)$ \\
Death & $226(27.5 \%)$ & $45(39.5 \%)$ \\
Alive & $543(66.1 \%)$ & $63(55.3 \%)$ \\
LFU & $249(30.3 \%)$ & $23(20.2 \%)$ \\
\hline Stem cell support & PSCT: $8(1.0 \%)$ & BMT: 1 \\
& BMT: $4(0.5 \%)$ & $(0.9 \%)$ \\
\hline Family history & $8(1.0 \%)$ & $1(0.9 \%)$ \\
Second malignancy & $7(0.9 \%)$ & \\
\hline Post organ transplant & $7(0.9 \%)$ & \\
Kidney & $9(1.1 \%)$ & \\
Liver & $1(1.0 \%)$ & \\
BMT & $1(1.0 \%)$ & \\
\hline
\end{tabular}

$\mathrm{CTH}=$ Chemotherapy; $\mathrm{RTH}=$ radiotherapy; $\mathrm{CR}=$ complete remission; $\mathrm{PR}=$ partial remission; $\mathrm{BMT}=$ bone marrow transplantation; $\mathrm{LFU}=$ last follow-up.

difference observed from about 4 per 100,000 in Slovakia to about 8 per 100,000 in The Netherlands. The total proportion classified as being of extranodal origin ranged from to $22-25 \%$ of all lymphomas in the USA to $33 \%$ in Denmark and $34 \%$ in Israel. France (42\%) and Kuwait (43\%) had particularly high relative extranodal lymphoma frequencies.

The relative incidence of the subtypes of NHL is also known to differ according to the geographical location [13-15]. From a cohort of 1,403 cases of NHL at nine study sites around the world that consisted of consecutive patients seen between 1988 and 1990, 31\% presented as DLBCL, and $22 \%$ as follicular lymphomas. In a second major study, as part of a clinical evaluation of the International Lymphoma Study Group (ILSG), 1,378 NHL were classified from eight different geographic sites (Omaha, USA; Vancouver, Canada; Cape town, South Africa; London, UK; Würzburg/Göttingen, Germany; Lyon, France; Locarno/Bellinzona, Switzerland; and Hong Kong, China) [14]. Substantial differences were found in the distribution of the major subtypes of NHL: A greater percentage of follicular lymphoma was seen in North America, UK and South Africa (31\%) versus only 14\% in other sites. Peripheral T-cell lymphoma was most common in London, Cape Town and Hong Kong (9\%), whereas all other sites had a much lower incidence (average 3\%). In Switzerland higher percentages of mediastinal large Bcell lymphoma ( 9 vs. $2 \%$ elsewhere) and mantle cell lymphoma (14 vs. $6 \%$ elsewhere) were observed. In Kuwait, DLBCL with $58.6 \%$ of all NHL was by far the most common malignancy of the immune system in the adult group. Follicular lymphomas were considerably less frequent, accounting for only $4.6 \%$ of the cases. In a recent study of ILSG [12], a much higher number of follicular lymphoma $(22 \%)$ was found in nine sites around the world. In children, the far most common malignancy in our study was BL (77.2\%), followed by DLBCL (14\%). Our results confirm and extend older studies on NHL in the Middle East [16, 17], demonstrating a high incidence of extranodal lymphomas in this area. In a recent study in Bahrain [18], also a remarkable high number of primary extranodal lymphomas ( $41.7 \%$ of NHL) was found. This study and our results highlight common features of malignant lymphomas from countries of the Arabian Gulf region. The observed regional pattern distinguish them from lymphomas in the Western world, but the reasons for the high incidence of extranodal lymphomas in the Arabian Gulf region are largely unknown. It has been put forward [4] that this may be due to special ethnic or local environmental conditions, but our data do not support this assumption. Recent results from the KCCC [19] show that our Asian patients show a similar high number of extranodal lymphomas as Arabian people, excluding the hypothesis of an ethnic disposition. As the KCCC also treats a high number of lymphoma cases from the neighboring Gulf States (Saudi Arabia, Bahrain, Oman) and from other countries of the Middle East (Egypt, Syria, Lebanon, Yemen, Jordan), who also show a high incidence of extranodal NHL, a local environmental factor can be ruled out for Kuwait.

Our finding also supports the opinion that the distribution of NHL subtypes differs by geographic region [4]. In our study, the most common site of extranodal lymphoma involvement was the stomach (19.9\%) followed by the skin (17.8\%). The percentage of all lymphomas found in the stomach varies significantly in different countries. It ranged from 3\% in Costa Rica to 10\% in Italy and Spain [4]. In Kuwait the incidence of gastric and small intestine disease is especially high. In industrialized countries, small bowel cancers are predominantly adenocarcino- 
mas, whereas in developing countries, lymphomas are much more common [20]. Therefore, geographical and ethnical differences in the incidence of extranodal lymphomas at special sites show some interesting pattern that may not only reflect differences in coding practice, but also rather true variations in the incidence of extranodal lymphomas in various organs.

The male to female ratio for NHL in North American was 1.5:1 for the Caucasian population and 1.7:1 for African Americans [21]. Only lymphoma of the thyroid was more common in women $(0.4: 1)$ excluding sex-specific sites. For gastrointestinal NHL [22], found in a 15-year series in France, an age-standardized incidence rate of 0.94 per 100,000 for men, and a significantly smaller increase of 0.54 per 100,000 for women was seen. In our study the male to female ratio, both in the adult age group (2.1:1) and in the pediatric group (2.0:1), was shifted towards a significantly higher percentage of male patients.

A worldwide study of the International Agency for Research of Cancer, involving more than fifty countries, has provided data that the highest incidence of BL occurred in tropical Africa and Papua New Guinea [23]. Elsewhere, BL was rare, though the incidence was somewhat higher in Spain and North Africa. In Kuwait, NHL in children is the second most common malignant tumor [24]. We could demonstrate that the overwhelming majority (77.2\%) was BL followed by DLBCL. Nearly $90 \%$ $(88.6 \%)$ of the patients in the pediatric group had nodal involvement, and in half of them the bowel was affected. In children also, the majority of extranodal lymphomas was found to be in stage III and IV. The course showed a somewhat less favorable response to treatment in children (CR of $63.2 \%$ in children compared to $71.4 \%$ in adults) and the nonresponse rate was $21.9 \%$ compared to $13.6 \%$ in the adult group. Death rate in the pediatric group (39.5\%) was considerably higher than in adults (27.5\%), but a recent study done in Kuwait demonstrated that the treatment of NHL according to the BFM 95 protocol could significantly improve the overall survival and disease-free interval [25].

Cancer incidence in patients who undergo transplantation varies considerably and ranges from 4 to $18 \%$ [23]. In an extensive study with 6,798 post-transplantation patients, Penn [25] demonstrated that lymphomas are among the predominant malignancies after organ transplantation. In our patients 11 cases of extranodal lymphomas were found after organ transplantation, mainly of the kidney. All of them developed aggressive disease with poor prognosis. No cases of NHL associated with AIDS were found in our study.

In summary, our retrospective study demonstrated that extranodal lymphomas accounted for nearly half $(45 \%)$ of all NHL diagnosed in the KCCC in the period between January 1985 and December 2000. The reasons for this high incidence, also observed in other countries of the Arabian Gulf region, are largely unknown. In the future, new techniques such as cytogenetic molecular analyses to identify subtype-specific etiological factors, evaluations of polymorphisms in genes involved in immune function, and the study of the role of environmental and occupational chemicals in NHL in Kuwait will help to clarify these questions.

\section{Acknowledgements}

The generous support of the Kuwait Ministry of Health and the continuous help of the International Lymphoma Study Group (IISG) is gratefully acknowledged.

\section{References}

1 Guerney KA, Cartwright RA, Gilman EEA: Descriptive epidemiology of gastrointestinal non-Hodgkin's lymphoma on a populationbased registry. Br J Cancer 1999;79:19291934.

2 Hauke RJ, Armitage JO: A new approach to non-Hodgkin's lymphoma. Intern Med 2000; 39:197-208.

3 Longo DL: Non-Hodgkin's lymphoma. Curr Opin Hematol 1994;1:295-302.
4 Newton R, Ferlay J, Beral V, Devesa SS: The epidemiology of non-Hodgkin lymphoma: Comparison of nodal and extranodal sites. Int J Cancer 1997;72:923-930.

5 Weisenburger DD: Epemiology on non-Hodgkin's lymphoma: Recent findings regarding an emerging epidemic. Ann Oncol 1994;5:9-24.

6 Uppenkamp M, Feller AC: Classification of malignant lymphoma: Onkologie 2002;25: 563-570.

7 Freeman C, Berg JW, Cutler SJ: Occurrence and prognosis of extranodal lymphomas. Cancer 1972;29:252-260.
8 Otter R, Gerrits WBJ, Sandt MMVD, Hermans J, Willemez R: The Lymphoma Study Group. Primary extranodal non Hodgkin's lymphomas. A survey of population-based registry. Eur J Cancer clin Oncol 1989;25:12031210.

9 D'Amore F, Christensen BE, Brincker H, Pedersen NT, Thorling K, Hastrup P, Pedersen M, Jensen MK, Johansen P, Andersen E, Back B, Sorensen E: Clinico-pathological features and prognostic factors in extranodal Hodgkin lymphomas. Eur J Cancer 1991;27:1201-1208. 
10 Krol AD, leCessie S, Snijder S, Kluin-Nelemans JC, Kluin PM, Noordijk EM: Primary extranodal non-Hodkin's lmyphoma (NHL): The impact of alternative definitions tested in the Comprehensive Cancer Centre West population-based NHL registry. Ann Oncol 2003; 14:131-139.

11 Zeeb H, Blettner M: Increasing incidence and mortality of non-Hodgkin lymphomas. An epidemiological review of recent studies on risk factors for non-Hodgkin lymphoma. Med Klin 2001;96:87-100.

12 Gospodarowicz MK, Sufcliffe SB: The extranodal lymphomas. Semin Radiat Oncol 1995; 5:281-300.

13 Harris NL, Jaffe ES, Diebold J, Flandrin G, Müller-Hermelink HK, Vardiman J, Lister TA, Bloomfield CD: The World Health Organization classification of the haematopoietic and lymphoid tissues: Report of the Clinical Advisory Committee Meeting, Airlie House, Virginia, 1997. Histopathology 2000;36:6987.
14 Anderson JR, Armitage JO, Weisenburger DD: Epidemiology of the non-Hodgkin's lymphoma: Distribution of the major subtypes differ by geographic locations. Non-Hodgkin's lymphoma classification project. Ann Oncol 1998;9:717-720.

15 Ohshima K, Suzumiya J, Kikuchi M: The World Health Organization classification of malignant lymphoma incidence and clinical prognosis in HTLV-1-endemic area of Fukuoka. Pathol Int 2002;52:1-12

16 Bamanikar S, Thunhold S, Devi KR, Bamanikar A: The pattern of malignant lymphoma in Oman. J Trop Med Hyg 1995;98:351-354.

17 Castella A, Joshi S, Raaschou T, Mason N: Acta Oncol 2001;40:660-664.

18 Shome DK, George SM, Al-Hilli F, Satir AA Spectrum of malignant lymphomas in Bahrain. Leitmotif of a regional pattern. Saudi Med J 2004;25:164-167.

19 Baker H, Al-Jarallah M, Manguno H, Temmim L, Madda JP, Sinowatz F: Clinical characteristics and pathological classification of non-Hodgkin's lymphoma in Kuwait. Results of a colloborative study with the International Lymphoma Study Group (ILSG). Leuk Lymphoma 2004;45:1865-1871.
20 Neugut AI, Jacobson JS, Suh S, Mukherjee R, Arber N: The epidemiology of cancer of the small bowel. Cancer Epidemiol Biomarkers Prev 1998; 7:43-51.

21 Groves FD, Linet MS, Travis LB, Devesa SS: Cancer surveillance series: Non-Hodgkin's lymphoma incidence by histologic subtype in the United States from 1978 through 1995. J Natl Cancer Inst 2000;92:1240-1251.

22 Ducreux M, Boutron MC, Piard F, Carli PM, Faivre J: A 15-year series of gastrointestinal non-Hodgkin's lymphomas: A populationbased study. Br J Cancer 1998; 77:511-514.

23 Stiller CA, Parkin DM: International variation in the incidence of childhood lymphomas. Paediatr Perinat Epidemiol 1990;4:303-324.

24 Mottl H, Bajcova V, Nemec J, Shenmari SA, Awadi SA: High survial rate in childhood NonHodgkin lymphoma without CNS involvement: Results of BFM 95 study in Kuwait. Pediatr Hematol Oncol 2003;20:103-110.

25 Penn I: Incidence and treatment of neoplasias after transplantation. J Heart Lung Transplant 2001; 12:328-336. 